\title{
Representation strength in pigeon short-term memory: Effect of delay training
}

\author{
JANICE N. STEIRN \\ Georgia Southern University, Statesboro, Georgia \\ and \\ THOMAS R. ZENTALL and LOU M. SHERBURNE \\ University of Kentucky, Lexington, Kentucky
}

\begin{abstract}
An attempt was made to manipulate the strength of internal stimulus representations by exposing pigeons to brief delays between sample offset and comparison onset in a delayed conditional discrimination. In Experiment 1, pigeons were first trained on delayed conditional discrimination with either short $(0.5-\mathrm{sec})$ delays or no delays. When delays were increased by $2.0 \mathrm{sec}$, birds trained with a delay performed at a higher level than did birds trained with no delays. In Experiment 2, subjects were first trained on a delayed simple discrimination. Following a circle stimulus, responses to a white key were reinforced; however, following a dot stimulus, responses to the white key were not reinforced. The pigeons were then trained on a delayed conditional discrimination involving hue samples and line-orientation comparisons with differential outcomes. Choice of vertical following red yielded food; choice of horizontal following green yielded no food. Mixed delays were then introduced to birds in Group Delay, whereas birds in the control group received overtraining. When tested on a delayed simple discrimination with hue stimuli (red and green initial stimuli followed by white response stimulus), pigeons in Group Delay tended to perform at a higher level than did birds in the control group (i.e., although the birds in both groups responded more following red than following green, birds in Group Delay did this to a greater extent than did birds in the control group). Thus, experience with delays appears to strengthen stimulus representations established during training.
\end{abstract}

When an organism is presented with a stimulus, it is presumed that some internal representation of the stimulus results. Evidence for the existence of stimulus representations comes, for example, from the finding that an organism can learn to make a response appropriate to the presentation of a stimulus, long after the stimulus has been removed (see, e.g., Terrace, 1984). Although representations are not directly observable, they can be studied indirectly through the effect that they have on overt behavior (see, e.g., Roitblat, 1982; Terrace, 1984).

The delayed conditional discrimination task is often used in the study of representations. In a delayed conditional discrimination, an initial stimulus (sample) is presented and then removed. Some time later, choice stimuli (comparisons) are presented and the subject must choose one of the comparisons, on the basis of the sample that is no longer present. A representation apparently allows the

This research was supported by National Science Foundation Grant RII-8902792 to Janice N. Steirn, by National Science Foundation Grant BNS-8418275 to Thomas R. Zentall and Peter J. Urcuioli, and by a grant from the University of Kentucky Research Foundation to Thomas R. Zentall. We gratefully acknowledge the assistance of Joyce Jagielo, Kimberly Kelly, and James S. Miller in conducting Experiment 1, and Christopher Randall, Karen Roper, and Zhongbiao Zhang in conducting Experiment 2. Correspondence concerning this article should be sent to J. N. Steirn, Department of Psychology, Georgia Southern University, Statesboro, GA 30460. subject to span the delay between sample offset and comparison onset.

The ability of animals to maintain memory over long delays (e.g., Cook, Brown, \& Riley, 1985; Zentall, Steirn, \& Jackson-Smith, 1990) undoubtedly requires that the animal develop strong, memorable representations. Actually, there are a number of possible ways in which animals may learn to maintain accurate performances over long delays. First, the representation may become stronger, or more vivid, when the subject is trained with delays. Alternatively, the representation formed may be more durable. If the bird has learned that a delay will follow, it may learn to encode the initial stimulus more quickly, thus allowing more rehearsal time. Or, because of practice, the rehearsal process may be more efficient in delay-trained animals. Another possibility is that subjects given delay training may have more practice in relying on weakened representations as a basis for their response decision. Although little is known about the factors that affect the nature and strength of representations, certain factors are known to affect performance on delay tasks, and thus are presumed to affect representation strength.

One such factor is sample duration. Longer sample duration or increased responding to the sample, tends to result in higher performance levels across delays (e.g., Grant, 1976; Roberts, 1972; Roberts \& Grant, 1974). Similarly, repeated presentations of a sample also improve perfor- 
mance (Roberts, 1972). Thus, it appears that strength of a representation can be manipulated by manipulation of total sample presentation time.

Another factor influencing delay performance, and thus presumably the strength of representations, is the degree to which the event being represented is "surprising" or unexpected. In experiments using classical conditioning (Terry \& Wagner, 1975; Wagner, Rudy, \& Whitlow, 1973) and delayed conditional discriminations (Maki, 1979), evidence indicates that surprising events are remembered better than are expected events.

A third factor that appears to affect representation strength is the nature of the stimulus being represented. For instance, Farthing, Wagner, Gilmour, and Waxman (1977) found that, for pigeons, hues are more memorable than line orientations. Also, under certain conditions, spatial memory appears to be very robust in both rats and pigeons. For example, Beatty and Shavalia (1980) found that rats, on a radial arm maze, performed at high levels of accuracy after delays of up to $4 \mathrm{~h}$, and Zentall et al. (1990) found that pigeons could tolerate delays of at least $1 \mathrm{~h}$ in a spatial memory (radial-arm-maze analog) task.

The nature of the stimulus represented may also be affected by the nature of the trial outcome. In the differential outcomes (DO) procedure, for example, the choice of the correct comparison following one sample is reinforced with one outcome, whereas the choice of the correct comparison following the other sample is reinforced with a different outcome (Trapold, 1970). The use of DO results in rapid acquisition of the conditional discrimination (relative to control groups with nondifferential outcomes) and higher performance levels when delays are inserted between the sample and comparisons (e.g., Peterson, 1984; Peterson, Wheeler, \& Trapold, 1980). The high level of performance typically found with the DO procedure is presumed to derive from the fact that the stimulus representation consists of the highly memorable, different outcome expectancies, rather than (or in addition to) the visual sample alone (e.g., Peterson, 1984; Peterson \& Trapold, 1982). Results of DO research indicate that the representation that is maintained through the delay is not necessarily a neural trace of the sample stimulus.

In the studies cited above, delays have been used as a means of assessing the strength and nature of representations, but experience with delays may also directly affect the strength of the representation. If a conditional discrimination is learned with a short delay imposed between the offset of the sample and the onset of the comparisons, the subject would need to learn to maintain a representation of the sample during the delay in order for task acquisition to occur. If such a delay is not present, a less fully developed representation might suffice during task acquisition.

\section{EXPERIMENT 1}

The purpose of Experiment 1 was to determine if conditional discrimination training with a brief delay would encourage pigeons to use memory codes that would effectively transfer to longer delays to a greater extent than would conditional discrimination training with no delays.

\section{Method}

\section{Subjects}

The subjects were 12 mixed-sex, White Carneaux pigeons. They were retired breeders, 5-8 years old, obtained from the Palmetto Pigeon Plant (Sumter, SC). The pigeons were maintained at $75 \%-80 \%$ of their free-feeding weights and had free access to water and grit in their home cages. They were individually housed in wire cages in a colony room that was on a 12:12-h light:dark cycle.

\section{Apparatus}

Experimental sessions were conducted in a BRS/LVE three-key operant chamber with inside measurements $35 \mathrm{~cm}$ (high) $\times 30 \mathrm{~cm}$ (deep) $\times 35 \mathrm{~cm}$ (across the response panel). Mounted $25 \mathrm{~cm}$ above the chamber floor was a row of three round pecking keys, $2.5 \mathrm{~cm}$ in diameter and spaced $8 \mathrm{~cm}$ apart, center to center. Behind each pecking key was a 12-stimulus in-line projector (Industrial Electronics Engineering with General Electric No. 1820 lamps). Each projector could illuminate its corresponding key with a red $(R)$ or a green $(G)$ field (Kodak Wratten filters Nos. 26 and 60, respectively). The $6 \times 5 \mathrm{~cm}$ aperture to a rear-mounted grain feeder was directly below the center key, with its bottom edge $9.5 \mathrm{~cm}$ from the chamber floor. A feeder light illuminated the food whenever the feeder was raised. A shielded houselight was mounted $6 \mathrm{~cm}$ above the center pecking key. Masking of sounds was produced by an exhaust fan mounted on the outside of the chamber and by white noise at $72 \mathrm{~dB}$ provided through a speaker mounted on the inside of the chamber. Electromechanical control equipment was located in an adjoining room.

\section{Procedure}

Preliminary training. All pigeons were initially trained to eat from the feeder as soon as it was raised. Pecking a white center key was then shaped by the method of successive approximations. Over the next three sessions, the center-key response requirement was increased to 10 pecks. Each preliminary training session consisted of 48 reinforcements (2-sec access to Purina Pigeon grains). On the following session, either an R or a G stimulus was presented on the center key, and 10 pecks were required to turn it off and produce reinforcement. The hue presented on the center key ( $R$ or G) changed randomly following reinforcement. On the last session of preliminary training, a single $R$ or $G$ stimulus was presented on either the left or the right key, and a single peck resulted in reinforcement. The location of the lit key (left or right) and its hue changed randomly following each reinforcement.

Conditional discrimination training. On the day following preliminary training, all birds began training on the delayed conditional discrimination. Each trial began with the center key lit $R$ or G. Ten pecks to the center key (sample) turned it off and turned on the left and right (comparison) keys (one $\mathrm{R}$, the other $\mathrm{G}$ ). A single peck to the comparison key that matched the sample was reinforced and resulted in the start of a 10-sec intertrial interval (ITI). During the ITI, all the response keys were turned off and the houselight was turned on. A single peck to the other response key also started the ITI, but it did not result in reinforcement. The sample hue ( $R$ or $G$ ) and the location of the correct comparison key (left or right) were counterbalanced over each 96-trial session, and the same sample hue or the same side key could be correct on no more than three consecutive trials.

For birds in Group 0 (zero delay), there was no delay between the offset of the sample stimulus and the onset of the comparison stimuli. For birds in Group 0.5, there was a 0.5 -sec delay between the offset of the sample and the onset of the comparisons. In all other respects, training for the two groups was the same. 
Training proceeded for each bird on the delayed conditional discrimination until a performance criterion was reached of two consecutive sessions at or above $90 \%$ correct responding. As each bird reached this criterion, it was transferred to longer delays.

Transfer to longer delays. During transfer sessions, each bird in Group 0 was exposed to mixed-delay trials in which half of the trials were 0 -sec delay trials, as during original training, and the remaining trials had delays of $2 \mathrm{sec}$. Each bird in Group 0.5 was exposed to mixed-delay trials in which half of the trials had delays of $0.5 \mathrm{sec}$, as during training, and the remaining trials had delays of $2.5 \mathrm{sec}$. Thus, for all birds, all new trials in transfer involved an increase of $2.0 \mathrm{sec}$, relative to the delay on which they had been originally trained. All birds received four transfer sessions.

\section{Results and Discussion}

\section{Conditional Discrimination Training}

Group 0 acquired the conditional discrimination at a slightly faster rate ( 7.7 sessions) than did Group 0.5 (8.8 sessions); however, the difference in the rate of task acquisition between the two groups was not significant $[F(1,10)=1.45]$. In this and all subsequent analyses, significance is assessed relative to the .05 level.

\section{Delay Transfer}

A two-way analysis of variance (ANOVA) was performed on the data from the first transfer session, with group (0 vs. 0.5$)$ and delay (short vs. long) as factors. The analysis indicated that there was no significant effect of group $[F(1,10)=2.14]$, but there was a significant effect of delay $[F(1,10)=108.05]$ and a significant group $\times$ delay interaction $[F(1,10)=9.58]$. As can be seen from the mean performance scores plotted in Figure 1, performance on the short delays did not differ between the two groups. At the long delays, however, Group 0.5 performed $12.2 \%$ correct better than did Group 0 . An analysis of this simple main effect indicated

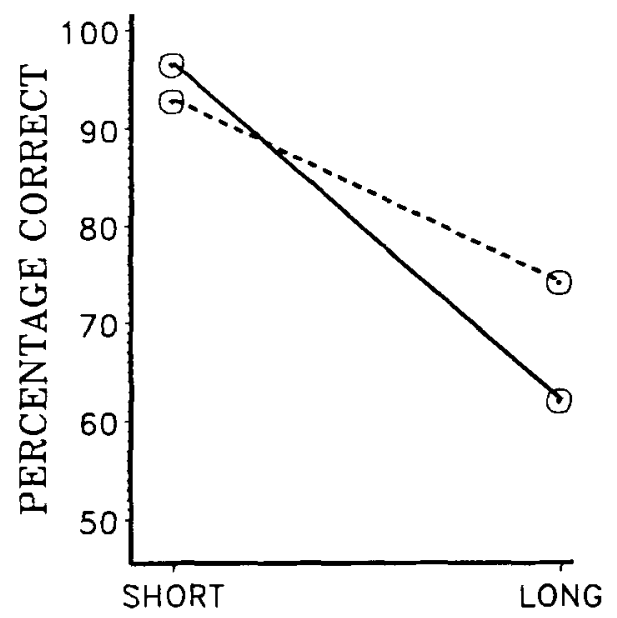

DELAY

Figure 1. Percentage correct on the first transfer session of Phase 2 for Group 0.5 (dotted line) and Group 0 (solid line) as a function of length of delay (SHORT $=$ delay received in training, LONG = training delay plus 2 sec) in Experiment 1. that the group effect was significant at the long delay $[F(1,10)=11.32]$

A three-way ANOVA was performed on the data from all four transfer sessions with group (0 vs. .5), delay (short vs. long), and session (1-4) as factors. The analysis indicated that although there was no significant effect of group $[F(1,10)=2.51]$, there were significant effects of delay $[F(1,10)=113.81]$ and session $[F(3,30)=3.81]$. The pigeons performed better at shorter delays than at longer delays, and performance improved over sessions. Furthermore, there was a significant group $\times$ delay interaction $[F(1,10)=7.23]$. Again, although there was little difference in performance between the two groups at the short delay, there was a $12.4 \%$ correct difference in matching performance at the long delay. An analysis of this simple main effect again indicated that the group effect was significant at the long delay $[F(1,10)=12.22]$. No other interaction associated with the three-way ANOVA was significant. Thus, the relations found on the initial test session were maintained over the test phase.

These results show that when acquisition of a delayed conditional discrimination includes even very brief delays of $0.5 \mathrm{sec}$, transfer to long delays is facilitated, relative to such long-delay transfer following training without delays. This transfer effect was found even though the increase in delay resulted in a longer absolute delay for birds in Group $0.5(2.5 \mathrm{sec})$ than for birds in Group $0(2.0 \mathrm{sec})$.

One interpretation of the long-delay transfer effect is that acquisition of the conditional discrimination with delays requires animals to form stimulus representations that allow them to remember over the delay. Animals that do not experience a delay during task acquisition are not as well prepared to form representations of those stimuli.

An alternative explanation for the results of Experiment 1 is possible, if one assumes that the relation between psychological time and physical time is not linear but is an exponential function, with an exponent less than 1 (e.g., Weber's law; see Gibbon, 1977). Although the absolute length of delay was longer for Group 0.5 , and the absolute increase in delay from training to transfer was equal for the two groups (i.e., $2.0 \mathrm{sec}$ ), the subjective increase in delay may have been greater for Group 0 than for Group 0.5. Thus, the effects found in Experiment 1 may be related to quantitative differences in subjective delay lengthening, rather than differences in the way the stimuli are processed under the two training conditions.

A second alternative explanation for better long-delay performance by birds in Group 0.5 is that delays were not novel for these birds. In other words, they had had experience with a period of darkness following the offset of the sample, prior to the onset of the comparison stimuli. The birds in Group 0, however, had not had such experience prior to the increase in delays, and they might not have been prepared to respond under these stimulus conditions.

A third alternative explanation involves the possibility that birds in Group 0.5 formed stronger associations be- 
tween the sample stimulus and the comparison response, rather than (or in addition to) a stronger representation upon which the comparison choice was based.

In order to distinguish among these alternatives, an experiment was designed in which the strength of the representation would be tested in a task different from that in which it was established. Using transfer to a task in which the associations established in training are no longer relevant, but in which the representations are relevant, allows examination of differences in representations while precluding the use of preestablished associations.

\section{EXPERIMENT 2}

Because of the alternative interpretations allowed by the design of Experiment 1, a different approach was taken in Experiment 2. Research on differential outcomes (DO) has indicated that, in training, when different stimuli are followed by the same outcome they can then substitute for each other (e.g., Edwards, Jagielo, Zentall, \& Hogan, 1982; Peterson, 1984). Edwards et al. trained pigeons on two conditional discriminations, in which one sample from each pair was associated with peas and the other sample was associated with wheat (i.e., correct responses to the comparisons following the sample resulted in these sample-specific reinforcers). Following acquisition, the samples associated with the same outcome were found to be interchangeable (i.e., they were related through their commonly elicited outcome expectancy).

Similarly, Peterson (1984, Group DD) trained pigeons simultaneously on a successive conditional discrimination and a successive simple discrimination, both involving DO. In each of the two discriminations, one stimulus was associated with one outcome and the second stimulus was associated with a different outcome (i.e., one stimulus from each discrimination shared a common outcome). Peterson found that if the interchanged stimuli shared a common outcome, then when the stimuli from the simple discrimination were substituted for the samples in the conditional discrimination, high levels of transfer performance were obtained. As in the Edwards et al. study, this finding indicates that the stimuli sharing a common outcome had become related or that they elicited common expectancies and the conditional choice was based on the expectancy (or representation) rather than the sample.

As stated earlier, a procedure in which representations (but not specific associations) are transferred across tasks would allow examination of manipulations intended to affect representation strength (while eliminating the alternative explanation of differences in association strengths). In order to do this, a DO procedure similar to Peterson's (1984) procedure was used in Experiment 2.

In Phase 1, the birds were trained on a delayed simple discrimination-that is, only a single pair of stimuli (circle and dot) were to be discriminated. Following a circle stimulus, responses to a white key were reinforced; following a dot, responses to the white key were followed by a no-food event (i.e., the feeder light only). A dis- crimination ratio of responses to white following circle relative to responses to white following dot was calculated and used as a measure of the strength of the outcome expectancy. An expectancy of food should lead to high levels of responding on the white key, whereas an expectancy of no food should lead to low levels of responding. In Phase 2, the birds were trained on a delayed conditional discrimination with differential outcome. Following a red sample, vertical- and horizontal-stimulus comparisons were presented, and selection of the vertical comparison resulted in food. Following a green sample, selection of the horizontal comparison produced a nofood event (the feeder light). Choice of the incorrect comparison following either sample (i.e., vertical following green or horizontal following red) resulted in trial repetition. In Phase 2, half of the birds (delay group) were given experience with delays between sample offset and comparison onset; for the other half (control group), sample offset and comparison onset were simultaneous. In Phase 3, sample stimuli from Phase 2 (red and green) were then substituted for the Phase 1 initial stimuli (circle and dot) in the delayed simple discrimination, but with nondifferential outcome (to avoid additional learning during the test). If, in Phase 2, the sample/outcome associations resulted in sample-elicited food/no-food expectancies similar to the expectancies elicited by the initial stimuli of Phase 1, then in Phase 3, all birds should show evidence of successful transfer. Furthermore, if the delay training in Phase 2 resulted in stronger representations of the outcome expectancies, then Phase 3 transfer for the delay group should be stronger than transfer for the control group.

\section{Method}

\section{Subjects}

Twelve mixed-sex, experimentally naive, White Carneaux pigeons served as subjects. The birds were retired breeders, approximately 8-10 years old, obtained from Palmetto Pigeon Plant (Sumter, SC). The birds were housed and maintained as in Experiment 1.

\section{Apparatus}

A standard (BRS/LVE) operant chamber was used, with interior dimensions of $33 \mathrm{~cm}$ (high) $\times 31 \mathrm{~cm}$ (deep) $\times 35 \mathrm{~cm}$ (across the response panel). The response panel contained a row of three rectangular ( $3 \mathrm{~cm}$ wide $\times 2.5 \mathrm{~cm}$ high) response keys that were centered $0.5 \mathrm{~cm}$ apart on the response panel. The bottom of the keys was $21 \mathrm{~cm}$ from the floor of the chamber. Mounted behind each key was a 12-stimulus in-line projector (Industrial Electronic Engineering, Series 10 with G.E. No. 1820 lamps) that could project onto the center key blue (B), red (R), and green (G) hues (Kodak Wratten filter Nos. 38A, 26, and 60, respectively), white (W) light, circle $(C$, white annulus, $16 \mathrm{~mm}$ outside diameter, $13 \mathrm{~mm}$ inside diameter) and white dot (D, $5 \mathrm{~mm}$ diameter) shapes, and onto the side keys three stripes (13 mm long $\times 3 \mathrm{~mm}$ wide white stripes separated by $3 \mathrm{~mm}$ ) in either a vertical (V) or horizontal $(\mathrm{H})$ orientation. Mixed grain was provided by a rear-mounted feeder accessed through a $6 \times 5 \mathrm{~cm}$ rectangular aperture, centered horizontally on the response panel, with the bottom edge $7 \mathrm{~cm}$ from the floor of the chamber. A white light (Sylvania, 120 PSB) located behind the response panel and above the feeder aperture operated whenever the feeder was operated; it could also be illuminated independently 
of the the feeder. A shielded houselight was mounted on the response panel, $5 \mathrm{~cm}$ above the center key. External noises were masked by white noise and an exhaust fan mounted on the outside of the chamber. Stimulus presentation and data collection were programmed on a microcomputer located in an adjacent room.

\section{Procedure}

Pretraining. All pigeons were magazine trained and were then shaped by the method of successive approximations to peck the center key. The hue on the center key alternated, B and W, randomly between reinforcements.

Phase 1. All birds received training on a delayed simple discrimination. A trial started with a B warning stimulus on the center key. The warning stimulus remained lit until a single peck occurred. Termination of the warning stimulus was accompanied by illumination of either a C or D initial stimulus on the center key. The initial stimulus remained on the key for $6 \mathrm{sec}$. Responses to the initial stimulus were recorded, but had no programmed consequence. The initial stimulus was replaced by a $W$ center key. If the initial stimulus had been $\mathrm{C}$, the first response to $\mathrm{W}$ after $6 \mathrm{sec}$ (fixed interval, FI, $6 \mathrm{sec}$ ) resulted in termination of the stimulus and presentation of grain during the first $2 \mathrm{sec}$ of the 10 -sec ITI. The number of responses occurring during the first $6 \mathrm{sec}$ of the $W$ stimulus was recorded. If the initial stimulus had been $D$, the $W$ stimulus was turned off after $6 \mathrm{sec}$ and the feeder light was illuminated (but the feeder was not raised) during the first $2 \mathrm{sec}$ of the ITI (see Table 1 for design of Experiment 2). Responses on these trials were recorded, but had no programmed consequence. The order of initial stimulus presentation was randomly determined, with the restriction that the same stimulus could not be presented more than three trials in succession. Sessions consisted of 96 trials and were conducted 6 days a week.

For each session, a discrimination ratio (DR) was computed for each bird by dividing the number of responses to $W$ following $C$ by the number of responses to $\mathrm{W}$ following both $\mathrm{C}$ and $\mathrm{D}$. The birds were maintained on Phase 1 for a minimum of eight sessions and until they reached a performance criterion of 2 consecutive days with a DR of .90 or better.

Phase 2. Phase 2 consisted of training on a delayed conditional discrimination with differential outcome. A trial began with presentation of B on the center key. A single peck to B resulted in its termination and illumination of the center key with a sample, either $R$ or $G$. The sample remained illuminated for $6 \mathrm{sec}$, with no scheduled consequence for responses. Upon termination of the sample, the two side keys were illuminated, one with a V comparison stimulus and the other with an $\mathrm{H}$ comparison. A single peck to either comparison resulted in the termination of both comparisons. A response to $\mathrm{V}$ following an $\mathrm{R}$ sample resulted in access to grain for the first $2 \mathrm{sec}$ of the ITI. A response to $\mathrm{H}$ following a $\mathbf{G}$ sample resulted in feeder illumination during the first $2 \mathrm{sec}$ of the ITI. An incorrect response (to $\mathrm{H}$ following $\mathrm{R}$ or to $\mathrm{V}$ following $\mathrm{G}$ ) resulted in an ITI followed by trial repetition. Choices on correction trials were not included in the calculation of percent cor- rect performance. Order of sample presentation and position of comparisons on the keys were randomly determined, except that on no more than three successive trials could (1) a particular sample appear, (2) the position of the correct comparison be the same, or (3) a particular comparison be correct. Each session consisted of 96 trials.

The birds were trained on Phase 2 for a minimum of 8 days and to a criterion of 2 consecutive days with performance of at least $90 \%$ correct. As the birds reached criterion on Phase 2, they were matched (in pairs) for number of sessions to reach criterion in Phases 1 and 2 combined. One bird from each matched pair was then randomly assigned to the delay group; the other bird was assigned to the control group. Birds in the delay group continued Phase 2 training, with delays of $0,4,8$, and $16 \mathrm{sec}$ inserted between sample offset and comparison onset. Delays were equally distributed across samples and randomly distributed across trials, except that the same delay could not occur on more than three consecutive trials. Delay training for birds in the delay group continued for a minimum of 8 days and until performance of $90 \%$ or higher was obtained for 2 consecutive days. At that time, they were transferred to Phase 3. Each bird in the control group received overtraining on the conditional discrimination (no delays added) for the same number of sessions that its yoked (delay) partner received. At that time, they too were transferred to Phase 3 . All birds received 10 refresher trials $(5$ each of $\mathrm{C}$ and D) of the Phase 1 task following each Phase 2 session.

Phase 3. Phase 3 consisted of a delayed simple discrimination with nondifferential outcomes. The samples from Phase 2 ( $R$ and G) were substituted for the initial stimuli from Phase 1 (C and D). A trial began with the illumination of a $B$ warning stimulus. A single peck to $B$ terminated the warning stimulus and resulted in illumination of the center key with either $R$ or $G$. This stimulus remained on for $6 \mathrm{sec}$, after which it was replaced with a 6-sec $\mathrm{W}$ stimulus. Responses to W were recorded, but had no scheduled consequence. Following half of the trials (randomly determined), food was delivered for $2 \mathrm{sec}$; following the remaining trials, only the feeder light was presented. Deviations from chance (.50) DRs (involving responses to $\mathrm{W}$ following the food-associated sample divided by total $\mathrm{W}$ responses) were calculated for each bird for each session. Each bird remained on Phase 3 for a minimum of 5 days and until its DR deviated from chance by no more than .05 for 2 consecutive days.

\section{Results and Discussion}

\section{Phase 1}

The birds required a mean of 16.3 sessions to acquire the delayed simple discrimination to criterion. Birds assigned to the delay group and the control group did not differ significantly in the number of sessions to criterion (means $=16.2$ and 16.5, respectively; $F<1$ ).

Table 1

Design of Experiment 2

\begin{tabular}{|c|c|c|c|}
\hline \multirow{2}{*}{$\begin{array}{c}\text { Delayed } \\
\text { Simple Discrimination } \\
\text { Acquisition }\end{array}$} & \multicolumn{2}{|c|}{$\begin{array}{c}\text { Delayed } \\
\text { Conditional Discrimination }\end{array}$} & \multirow{2}{*}{$\begin{array}{c}\text { Delayed } \\
\text { Simple Discrimination }\end{array}$} \\
\hline & Acquisition & Delays & \\
\hline \multicolumn{4}{|c|}{ Delay Group } \\
\hline$C \rightarrow W(F)$ & $R(0) \rightarrow V(F)$ & $0,4,8,16$ & $R(0) \rightarrow W(F / N F)$ \\
\hline $\mathrm{D} \rightarrow \mathrm{W}(\mathbf{N F})$ & $\mathrm{G}(0) \rightarrow \mathrm{H}(\mathrm{NF})$ & $0,4,8,16$ & $\mathrm{G}(0) \rightarrow \mathrm{W}(\mathrm{F} / \mathrm{NF})$ \\
\hline \multicolumn{4}{|c|}{ Control Group } \\
\hline $\mathrm{C} \rightarrow \mathrm{W}(\mathrm{F})$ & $R(0) \rightarrow V(F)$ & 0 & $\mathrm{R}(0) \rightarrow \mathrm{W}(\mathrm{F} / \mathrm{NF})$ \\
\hline $\mathrm{D} \rightarrow \mathrm{W}(\mathrm{NF})$ & $\mathrm{G}(0) \rightarrow \mathrm{H}(\mathrm{NF})$ & 0 & $\mathrm{G}(0) \rightarrow \mathrm{W}(\mathrm{F} / \mathrm{NF})$ \\
\hline
\end{tabular}

Note $-\mathrm{C}=$ circle, $\mathrm{D}=$ dot, $\mathrm{W}=$ white, $\mathrm{F}=$ food, $\mathrm{NF}=$ no food, $\mathrm{R}=$ red, $\mathrm{G}=$ green.

Test involves nondifferential reinforcement. 


\section{Phase 2}

The birds required an average of 8.1 sessions to reach criterion on the delayed conditional discrimination. Again, the number of sessions to criterion did not differ significantly for birds in the delay and control groups ( 7.5 and 8.7 sessions, respectively; $F<1$ ).

The initial effect of delays on performance was examined for birds in the delay group. A one-way repeated measures ANOVA was performed on percent correct scores at each of the four delays averaged over the first four sessions of delay. Performance did not differ significantly as a function of delay (mean correct for delays of $0,4,8$, and $16 \mathrm{sec}=85.1 \%, 85.6 \%, 85.8 \%$, and $83.5 \%$, respectively; $F<1$ ). The high level of performance over relatively long retention intervals (up to $16 \mathrm{sec}$ ) can undoubtedly be attributed to the DO procedure (see, e.g., Peterson, Linwick, \& Overmier, 1987).

\section{Phase 3}

Discrimination ratios for the first transfer session were .71 for the delay group and .60 for the controls. Thus, transfer performance (difference between the DR and chance) was positive for both groups (.21 and .10 for delay and control groups, respectively). The DRs for both groups differed significantly from chance $(.50)[t(5)=$ 2.73 and 4.05 , respectively].

The correlation between sessions to criterion on Phases 1 and 2 and Phase 3 performance was moderate, but not significant $[r(10)=-.37]$. This indicates that speed of learning in Phases 1 and 2 was somewhat related to performance, and it supports the choice of the sessions-tocriterion variable as a matching variable.

In all pairs but one, the subject in the delay group transferred at a higher level than did the yoked-control partner (see Table 2). In the one exception, the delay bird failed to show positive transfer. When the pair containing that bird was eliminated from the data, a dependent $t$ test indicated that the delay group transferred at a significantly higher level (mean DR $=.76$ ) than did the control group (mean DR $=.61$ ) $[t(4)=2.61]$. However, with the data from the pair involving the one deviant included, the superiority of the delay group was not significant $[t(5)=1.78]$.

The results from Experiment 2 suggest that representations of a food outcome established in a delayed conditional discrimination can substitute for representations of

Table 2

Transfer Performance of Control and Delay Subjects (Relative to Chance)

\begin{tabular}{ccc}
\hline Subject Pair & Control & Delay \\
\hline 1 & .15 & .46 \\
2 & .07 & .17 \\
3 & .04 & .05 \\
4 & .05 & -.04 \\
5 & .09 & .34 \\
6 & .19 & .26 \\
Mean & .10 & .21 \\
\hline
\end{tabular}

a food outcome elicited by different stimuli, established in a delayed simple discrimination. This result is consistent with the results of Peterson (1984) and Edwards et al. (1982). Additionally, DO representations supported high levels of performance with delays of up to $16 \mathrm{sec}$. The absence of a statistically significant delay effect is an indication of the strength of the outcome representations.

In Phase 3, the representations of outcome events elicited by Phase 2 stimuli resulted in higher DRs in the delay group than in the control group. This finding suggests that training with delays might have increased outcome representation strength.

\section{GENERAL DISCUSSION}

In Experiment 1, initial delayed conditional discrimination training with a short delay resulted in better longdelay performance than when initial training involved no delays. However, even though the training delays were brief, it is possible that task-specific experience with delays might have contributed to the differential long-delay transfer effects. In Experiment 2, this problem was eliminated by using a delayed simple discrimination in Phases 1 and 3 so that both the delay and control groups had comparable experience with this task. Furthermore, the critical test phase involved no delays for either group. The only difference between the two groups was in the delay experienced in the context of the conditional discrimination training in Phase 2. Thus, the results of Experiment 2 supported those of Experiment 1. In both experiments, representations established under delay conditions were apparently stronger than those established without delays. Evidence that the strengthening of representations through exposure to delay procedures (Phase 2 of Experiment 2) occurs in the absence of delays (Phase 3 ) suggests that delay training is a vehicle for increasing representation strength, but is not part of the context required for its demonstration.

The present research may also have implications for other research areas, such as directed forgetting. In a typical directed-forgetting task (e.g., Grant, 1981; Maki \& Hegvik, 1980), a delayed conditional discrimination is trained with either a remember cue or a forget cue presented during the delay. On trials in which the remember cue is presented, comparisons follow the delay. On trials in which the forget cue is presented, no test follows the forget cue (i.e., the delay is followed by the ITI). On infrequently presented probe trials, in which the forget cue is followed by comparisons, performance is generally much lower than is performance on remember-cue trials. The results of directed-forgetting research indicate that animals may learn to differentially remember following a remember cue (or, conversely, they may learn to not remember following a forget cue). In the experiments presented here, it is possible that, for the birds trained with delay, the sample served as an "instruction" to remember, whereas the birds trained with no delays were not so instructed. Although the present experiments were con- 
ducted between groups (whereas directed forgetting is a within-subject phenomenon), the samples (followed by delays) may be seen in this context as remember cues.

As mentioned earlier, there are a number of ways in which delay training might affect the representation. The strength of the representation may be increased, or the representation may become more durable. The initial stimulus may be encoded more quickly allowing more rehearsal time, or rehearsal itself may become more efficient. Another possibility is that birds trained with delays may be better able to use weakened representations as a basis for their response decision. Whatever the underlying mechanism, the present data suggest that experience with delays can affect a pigeon's ability to deal with representations of initial stimuli, even in the absence of delays.

\section{REFERENCES}

Beatty, W. W., \& Shavalia, D. A. (1980). Spatial memory in rats: Time course of working memory and effect of anesthetics. Behavioral Biology, 28, 454-462.

Cook, R. G., Brown, M. F., \& Riley, D. A. (1985). Flexible memory processing by rats: Use of prospective and retrospective information in the radial maze. Journal of Experimental Psychology: Animal Behavior Processes, 11, 453-469.

Edwards, C. A., Jagielo, J. A., Zentall, T. R., \& Hogan, D. E. (1982). Acquired equivalence and distinctiveness in matching to sample by pigeons: Mediation by reinforcer-specific expectancies. Journal of Experimental Psychology: Animal Behavior Processes, 8, 244-259.

Farthing, G. W., Wagner, J. M., Gilmour, S., \& Waxman, H. M. (1977). Short-term memory and information processing in pigeons. Learning \& Motivation, 8, 520-532.

GibBon, J. (1977). Scalar expectancy theory and Weber's Law in animal timing. Psychological Review, 84, 279-325.

Grant, D. S. (1976). Effect of sample presentation time on long-delay matching in the pigeon. Learning \& Motivation, 7, 580-590.

GraNT, D. S. (1981). Stimulus control of information processing in pigeon short-term memory. Learning \& Motivation, 12, 19-39.

MAKI, W. S. (1979). Pigeon's short-term memories for surprising vs. expected reinforcement and nonreinforcement. Animal Learning \& Behavior, 7, 31-37.
MaKı, W. S., \& Hegvik, D. K. (1980). Directed forgetting in pigeons. Animal Learning \& Behavior, 8, 567-574.

Peterson, G. B. (1984). How expectancies guide behavior. In H. L. Roitblat, T. G. Bever, \& H. S. Terrace (Eds.), Animal cognition (pp. 135-148). Hillsdale, NJ: Erlbaum.

Peterson, G. B., Linwick, D., \& Overmier, J. B. (1987). On the comparative efficacy of memories and expectancies as cues for choice behavior in pigeons. Learning \& Motivation, 18, 1-20.

Peterson, G. B., \& Trapold, M. A. (1982). Expectancy mediation of concurrent conditional discriminations. American Joumal of Psychology, 95, 571-580.

Peterson, G. B., Wheeler, R. L., \& Trapold, M. A. (1980). Enhancement of pigeons' conditional discrimination performance by expectancies of reinforcement and nonreinforcement. Animal Learning \& Behavior, 8, 22-30

ROBERTS, W. A. (1972). Short-term memory in the pigeon: Effects of repetition and spacing. Journal of Experimental Psychology, 94, 74-83.

Roberts, W. A., \& Grant, D. S. (1974). Short-term memory in the pigeon with presentation time precisely controlled. Learning \& Motivation, 5, 393-408.

Roitblat, H. L. (1982). The meaning of representation in animal memory. Behavioral \& Brain Sciences, 5, 353-406.

Terrace, H. S. (1984). Animal cognition. In H. L. Roitblat, T. G. Bever, \& H. S. Terrace (Eds.), Animal cognition (pp. 7-28). Hillsdale, NJ: Erlbaum

TERRY, W. S., \& Wagner, A. R. (1975). Short-term memory for "surprising" versus "expected" unconditioned stimuli in Pavlovian conditioning. Journal of Experimental Psychology: Animal Behavior Processes, 104, 122-133.

Trapold, M. A. (1970). Are expectancies based upon different positive reinforcing events discriminably different? Learning \& Motivation, 1, 129-140.

Wagner, A. R., Rudy, J. W., \& Whitlow, J. W. (1973). Rehearsal in animal conditioning. Journal of Experimental Psychology, 97, 407-426.

Zentall, T. R., Steirn, J. N., \& Jackson-Smith, P. (1990). Memory strategies in pigeons' performance of a radial-arm-maze analog task. Journal of Experimental Psychology: Animal Behavior Processes, 16, 358-371.

(Manuscript received January 9, 1992; revision accepted for publication September 28, 1992.) 